$$
\text { CONF-880417--15 }
$$

To be presented at the International Symposium on Fusion Nuclear Technology (ISFNT) to be held during the perlod of April 10-19, 1988, in Tokyo, Japan.

s.

\title{
RELATIONSHIP BETWEEN FABRICATION PARAMETERS AND STRUCTURAL CHARACTERISTICS OF SINTERED LITHIUM ORTHOSILICATE*
}

by CONF-880417--15

C. Y. Chu ${ }^{a}, K, B a r^{b}, J . B$. Singh,

DE88 009935

R. B. Poeppel, and M. C. Billone

Argonne National Laboratory

9700 S. Cass Ave.

Argonne, IL 60439

February 1988

* Work supported by the U. S. Department of Energy/Office of Fusion Energy under Contract W-31-109-Eng-38.

${ }^{a_{\text {Work }}}$ performed in partial fulfillment of requirements for $M$. S. Degree, Illinois Institute of Technology, Chicago, IL 60616.

bon leave from the Institute of Reactor Materials, Nuclear Research Center ¡170 Julich, Federal Republic of Germany. 


\title{
RELATIONSHIP BETWEEN FABRICATION PARAYETERS AND STRUCTURAL CHARACTERISTICS OF SINTERED LITHIUM ORTHOSILICATE*
}

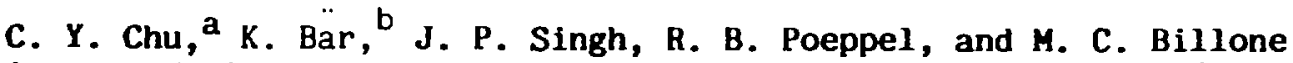

Argonne National Laboratory, 9700 S. Cass Ave., Argonne, IL 60439 U.S.A.

\section{ABSTRACT}

Lithium orthosilicate $\left(\mathrm{Li}_{4} \mathrm{SiO}_{4}\right)$ powder was synthesized by the solid-state reaction of lithium oxide with amorphous silica, and the effects of fabrication parameters on the structural characteristics of the product were investigated. Processing considerations such as milling media, drying technique, calcination time and temperature, pressing behavior, sintering time and temperatures, and impurity concentration were addressed. The initial powder particle size was observed to be important in achieving high sintered density, with densities as high as 98\% TD achieved with a particle size of approximately $1 \mu \mathrm{m}$.

\section{DISCLAIMER}

\begin{abstract}
This report was prepared as an account of work sponsored by an agerc; if lice i niled Stales Government. Neither the United States Government nor any agency thereof, iws any of thes employees, makes any warranty, express or implied, or assumes any legal hahuit, ur responsthility for the accuracy, completeness, or usefulness of any information, apparatus, product, or process disclosed, or represents that its use would not infringe privately owned rights. Reference herein to any specific commercial product, process, or service by trade name, trademark. manufacturer, or otherwise does not necessarily constitute or imply its endorsement, recommendation, or layoring by the United States Government or any agency thereof. The views and opinions of authors expressed herein do not necessarily state or reflect those of the United States Government or any agency thereof.
\end{abstract}

* Work supported by the U.S. Department of Energy/Office of Fusion Energy under Contract $W-31-109-E n g-38$.

a Work performed in partial fulfillment of requirements for M.S. degree, Illinois Institute of Technology, Chicago, IL 60616, U.S.A.

b On leave from the Institute of Reactor Materials, Nuclear Research Center, $5170 \mathrm{Julich}$, Federal Republic of Germany. 
RELATIONSHIP BETWEEN FABRICATION PARAMETERS AND STRUCTURAL CHARACTERISTICS OF SINTERED LITHIUM ORTHOSILICATE

C. Y. Chu, K. Bär, J. P. Singh, R. B. Poeppel, and M. C. Billone

Argonne National Laboratory, 9700 S. Cass Ave., Argonne, IL 60439 U.S.A.

\section{INTRODUCTION}

Lithium orthosilicate $\left(\mathrm{Li}_{4} \mathrm{SiO}_{4}\right)$ is a candidate tritium breeder blanket material for fusion reactors because of its high lithium content and comparatively high stability with respect to other lithium-containing compounds. Desirable structural characteristics for this application include small grain size and a density of 85-90\% TD. Conventional ceramic fabrication methods were used to prepare $\mathrm{Li}_{4} \mathrm{SiO}_{4}$ powder and each fabrication step was further investigated to illustrate the relationships between fabrication parameters and structural characteristics.

\section{FABRICATION PROCESS}

$\mathrm{Li}_{4} \mathrm{SiO}_{4}$ powder was prepared by solid-state reaction of lithium oxide and silica. Stoichiometric amounts of lithlum carbonate and amorphous silica were suspended in isopropanol. Isopropanol is a better grinding fluid for this application than short-chain alcohols because it absorbs less water and does not cause color formation [1]. The suspension was ball milled with zirconia media. The intimate mixture of $2 \mathrm{Li}_{2} \mathrm{CO}_{3} \cdot \mathrm{SiO}_{2}$ in the suspension was then pan dried in air. Calcination and reaction of the pan-dried powder at $650^{\circ} \mathrm{C}$ for 72 hours followed. The calcined powder was examined by $x$-ray diffraction analysis to identify the crystal structurs and by Inductively Coupled Plasma/Atomic Emission Spectroscopy to analyze the chemical elements. After the addition of 2.5 wt\$ Carbowax 400 (polyethylene glycol) to the calcined powder, the mixture was ball milled in isopropanol for homogeneity. Final powder was obtained by spray drying the suspension. The spray-dricd powder 
was cold pressed into cylindrical pellets and rectangular bars at selected pressures in the range of $124.1 \mathrm{MPa}$ to $193.1 \mathrm{MPa}$. A green density as high as $68 \%$ of theoretical (TD=2.39 $\left.\mathrm{g} / \mathrm{cm}^{3}\right)$ was achieved [2]. The pellets and bars were sintered at temperatures between 900 and $1100^{\circ} \mathrm{C}$. Sintered densities between 70 and 98\% TD were achieved. Both the green and sintered densities were determined geometrically.

\section{VARIATIONS OF PROCESSING PARAMETERS}

Two different milling media were tried: $\mathrm{Al}_{2} \mathrm{O}_{3}$ and $\mathrm{ZrO}_{2}$. Chemical analysis and $x$-ray diffraction data indicated that the wearing rate of alumina media during the ball-milling stage was higher than for zirconia media. Hence, $\mathrm{ZrO}_{2}$ media were used for all milling procedures in this study in order to minimize contamination. $\mathrm{ZrO}_{2}$ has a higher bulk density $\left(5.4 \mathrm{~g} / \mathrm{cm}^{3}\right)$ than $\mathrm{Al}_{2} \mathrm{O}_{3}\left(3.6 \mathrm{~g} / \mathrm{cm}^{3}\right)$. The use of high-density milling media not only reduces the amount of contamination, but also gives rise to faster grinding rates.

Two drying techniques, pan drying and spray drying, were used. Experimental results indicated that spray-dried powder is more sinterable than pan-dried powder [3]. In the present study, the initial particle size of amorphous silica powder $(0.014 \mathrm{\mu m})$ was much smaller than that of lithium carbonate powder $(12 \mu \mathrm{m})$. Thus, the silica tended to be ventilated away during spray drying, resulting in a non-stolchiometric product. To eliminate this problem, the suspension of $2 \mathrm{Li}_{2} \mathrm{CO}_{3} \cdot \mathrm{SiO}_{2}$ had to be pan-dried. Spray drying was then applied to the $\mathrm{Li}_{4} \mathrm{SiO}_{4}$ suspension just before pressing in order to increase the sinterability of the powder.

The pan-dried powder mixture was calcined at $650^{\circ} \mathrm{C}$ for different times in order to determine the appropriate calcining schedule. With a long-duration calcination treatment, strong interparticle bonds may be created between 
individual particles, resulting in the formation of aggregates [4]. On the other hand, with a short-duration treatment, the calcination reaction may not be completed and residual carbonate may be left. Residual carbonate is detrimental to the sintering of $\mathrm{Li}_{4} \mathrm{SiO}_{4}$ pellets, since the melting point of $\mathrm{Li}_{2} \mathrm{CO}_{3}$ is $718^{\circ} \mathrm{C}$, which is much lower than the sintering temperature of $\mathrm{Li}_{4} \mathrm{SiO}_{4}$ $\left(900-1100^{\circ} \mathrm{C}\right)$. Thus, a local melting of $\mathrm{Li}_{2} \mathrm{CO}_{3}$ might occur and eventually distort the shape of the sintered products. A 72-hours calcination at $650^{\circ} \mathrm{C}$ was sufficient for complete reaction. However, this calcination schedule resulted in coarse powder particles, which adversely affect sintering kinetics. Therefore, the calcined powder was ball milled to reduce the particle size.

The calcined powder was mixed with 2 wt\% binder and pressed in a uniaxial press. It was observed that double action (i.e., compression from both pressing sides) resulted in higher green density than single action (compression from the top only). The sintered density was, however; only weakly dependent on pressing pressure and more dependent on sintering temperature.

To evaluate the sintering behavior of $\mathrm{Li}_{4} \mathrm{SiO}_{4}$, the pressed body was sintered in air at different temperatures and for different times. For a given sintering temperature, as expected, the sintered density increased with time up to critical time. As shown in Fig. 1, the peak density was observed at a sintering time of 2 hours. Longer sintering resulted in excessive weight loss of specimens and extensive grain growth, leading to lower density, as shown in Fig. 1. For a given sintering time, similar behavior was observed in relation to sintering temperature (Fig. 2). A plot of weight loss as a function of time at $1075^{\circ} \mathrm{C}$ shown in Fig. 3, indicates a monotonic increase in weight loss with sintering time. In this figure, the corresponding density 
values are also indicated. The density initially increased with time and reaches a maximum value, after which it starts decreasing with time. The weight loss is probably due to volatilization during sintering, which results in weight loss and has detrimental effects on densification. Similar volatilization effects have been reported by Anderson [5] for sintering of $\mathrm{MgCr}_{2} \mathrm{O}_{4}$. Further studies are clearly needed to delineate this effect and optimize sintering atmosphere, time, and temperature. Our study shows that densification of $\mathrm{Li}_{4} \mathrm{SiO}_{4}$ occurs at temperatures as 1 ow as $700^{\circ} \mathrm{C}$. Thus, the soaking duration of the specimen above the densification temperature is also an important factor in determining the sintered density and grain size. A slow heating rate leads to a higher sintered density and larger grain size than a rapid heating rate, as shown in $\mathrm{Fig} .4$.

The initial powder particle size was observed to have a strong influence on the sintered density and the corresponding grain size. Our data showed that for an average particle size of $4.8 \mu \mathrm{m}$, the maximum density achieved after sintering for 2 hours at $1075^{\circ} \mathrm{C}$ was $93 \% \mathrm{TD}$, with an average grain size of $45 \mu \mathrm{m}$. On the other hand, for an average particle size of $1.15 \mu \mathrm{m}, \mathrm{a}$ density of $98 \%$ of TD with an average grain size of $25 \mu \mathrm{m}$ was obtained after sintering for 4 hours at $1000^{\circ} \mathrm{C}$. Figure 5 shows typical microstructures of the fractured surfaces of these two sintered products. Also, as expected, the smaller the initial particle size, the lower the sintering temperature required to achieve a given density (see Fig. 6).

Earlier work [6] has shown that metasilicate containing some orthosilicate can be sintered to as much as $95-96 \% \mathrm{TD}$ at $900^{\circ} \mathrm{C}$. This observation is believed to be related to the presence of a liquid phase during sintering. Our results indicated that the existence of a small amount of $\mathrm{Li}_{2} \mathrm{SiO}_{3}$ in $\mathrm{Li}_{4} \mathrm{SiO}_{4}$ allows sintering to as much as $97-98 \% \mathrm{TD}$ at $1000^{\circ} \mathrm{C}$ with powder of $1 \mu \mathrm{m}$ 
initial size. This behavior is believed to be due to low-melting eutectic phase formed at this temperature. Although the eutectic temperature between $\mathrm{Li}_{4} \mathrm{SiO}_{4}$ and $\mathrm{Li}_{2} \mathrm{SiO}_{3}\left(1204^{\circ} \mathrm{C}\right)$ [7] is much higher than the sintering temperature $\left(1000^{\circ} \mathrm{C}\right)$ in our study, the existence of some other impurities might decrease this eutectic temperature substantially, leading to liquid-phase formation at a relatively low temperature.

In view of the fact that $\mathrm{MgO}$ has :een used as a sintering aid to promote liquid-phase sintering in many ceramic systems [8], 0.2 wt $\$$ of Mg0 was added to $\mathrm{Li}_{4} \mathrm{SiO}_{4}$ powder to evaluate its effect on sintering. The MgO addition promoted densification at sintering temperatures below $1050^{\circ} \mathrm{C}$. At higher temperatures, the effect seemed to be diminished. Further study is required in order to understand the underlying mechanism of the improved sintering.

Another oxide that has been used to promote liquid-phase sintering is $\mathrm{SiO}_{2}$ [9]. The effect of excess $\mathrm{SiO}_{2}$ on the sintered density has been studied by adding 2 wt\% of $\mathrm{SiO}_{2}$ powder to $\mathrm{Li}_{4} \mathrm{SiO}_{4}$ powder. After sintering at $1000^{\circ} \mathrm{C}$ and above, the density of the product was slightly higher than that of stoichiometric $\mathrm{Li}_{4} \mathrm{SiO}_{4}$. This result is attributed to the formation or $\mathrm{Li}_{2} \mathrm{SiO}_{3}$, which leads to liquid-phase sintering.

\section{CONCLUSIONS}

1. There is a maximum sintered density for a given green-state density and temperature. Excessive ignition loss and the associated grain growth reduces the final sintered density.

2. Initial powder particle size is also an important factor in determining the maximum sintered density. With an average particle size of $4.8 \mu \mathrm{m}$, 
the maximum density that can be achieved is 937 TD; with an average particle size of $1.15 \mu \mathrm{m}$, a density of $98 \% \mathrm{TD}$ can be obtained.

3. The heating rate used to reach the sintering temperature also affects the sintered density. A fast heating rate produces a lower density than a slow heating rate.

4. Addition of $0.2 \mathrm{wtF} \mathrm{MgO}$ to $\mathrm{Li}_{4} \mathrm{SiO}_{4}$ powder promotes densification at sintering temperatures below $1050^{\circ} \mathrm{C}$, whereas addition of 2 wt\% $\mathrm{SiO}_{2}$ promotes liquid-phase sintering at $1000^{\circ} \mathrm{C}$ and above. However, residual carbonate is detrimental to the product and should be avoided. 
5. REFERENCES

[1] D. Vollath and $H$. Wedemeyer, "On the Preparation of the Lithium Silicates Series from $\mathrm{Li}_{2} \mathrm{SiO}_{3}$ to $\mathrm{Li}_{8} \mathrm{SiO}_{6}$ in Alcoholic Media," J. Nucl. Mater. $141-143(1986) 334-338$.

[2] D. Tranqui, R. D. Shannon, H. Y. Chen, S. I i jima and W. H. Baur, "Crystal Structure of Ordered $\mathrm{Li}_{4} \mathrm{SiO}_{4}$," Acta Cryst. B35 (1979) 2479-2487.

[3] M. D. Rasmussen, M. Akinc, D. Milius and M. G. McTaggart, "Effect of Spray Drying on the Sintering of $\mathrm{Y}_{2} \mathrm{O}_{3}$, Am. Ceram. Soc. Bull. 62 (2) (1985) 314-318.

[4] D. E. Niesz, R. B. Bennet and M. J. Snyder, "Strength Characterization of Powder Aggregates," Am. Ceram. Soc. Bull. 51 (1972) 677-680.

[5] H. U. Anderson, "Influence of Oxygen Activity on the Sintering of $\mathrm{MgCr}_{2} \mathrm{O}_{4}$, J. Am. Ceram. Soc. 57 (1974) 34-37.

[6] A. J. Flipot and P. Diels, "Relationship between Fabrication Parameters and Structural Characteristics of Sintered Lithium Metasilicate," J. Nucl. Mater. 141-143 (1986) 339-343.

[7] A. Skokan, H. Wedemeyer, D. Vollath and E. Günther, in: Proc. 14th Symp. on Fusion Technology, Avignon, France, Sept. 8-12, 1986, p. 1255. 
[8] C. Greskovich and C. O'Clair, "Effect of Impurities on Sintering $\mathrm{Si}_{3} \mathrm{~N}_{4}$ Containing MgO or $\mathrm{Y}_{2} \mathrm{O}_{3}$ Additives," Am. Ceram. Soc. Bull. $\underline{57}$ (1978) 1055-1056.

[9] J. F. Shackelford, P. S. Nicholson and W. W. Smeltzer, "Influence of $\mathrm{SiO}_{2}$ on Sintering of Partially Stabilized Zirconia," Am. Ceram. Soc. Bull. $\underline{53}$ (1974) 865-867. 


\section{FIGURE CAPTIONS}

Fig. I Sintered Density as a Function of $\mathrm{Time}$ at $1075^{\circ} \mathrm{C}$ (Heating rate $=$ $\left.100^{\circ} \mathrm{C} / \mathrm{h}\right)$

Fig. 2 Sintered Density as a Function of Temperature during 4-hr sintering period.

Fig. 3 Weight Loss as a Function of Sintering Time at $1075^{\circ} \mathrm{C}$. Numbers next to the data points represent the specimen density (\% TD).

Fig. 4 Comparison of Sintered Densities as a Function of Time at $1075^{\circ} \mathrm{C}$ for Two Different Heating Rates: $100^{\circ} \mathrm{C} / \mathrm{h}$ (ब) and $300^{\circ} \mathrm{C} / \mathrm{h}(\$)$. Numbers next to the data points represent the grain size ( $\mu \mathrm{m})$.

Fig. 5 Scanning Electron Micrographs of the Fractured Surfaces of Two Sintered Specimens: (a) 93\% TD Sintered at $1075^{\circ} \mathrm{C}$ for $2 \mathrm{hrs}$ and (b) $98 \% \mathrm{TD}$ Sintered at $1000^{\circ} \mathrm{C}$ for $4 \mathrm{hrs}$. Bars denote $10 \mu \mathrm{m}$.

Fig. 6 Sintered Density as a Function of Time at $1000^{\circ} \mathrm{C}$ and $1075^{\circ} \mathrm{C}$ with Initial Powder Particle Sizes of $4.8 \mu \mathrm{m}(\mathrm{x})$ and $1.15 \mu \mathrm{m}(\$)$. Numbers next to the data points represent the grain size $(\mu \mathrm{m})$. 

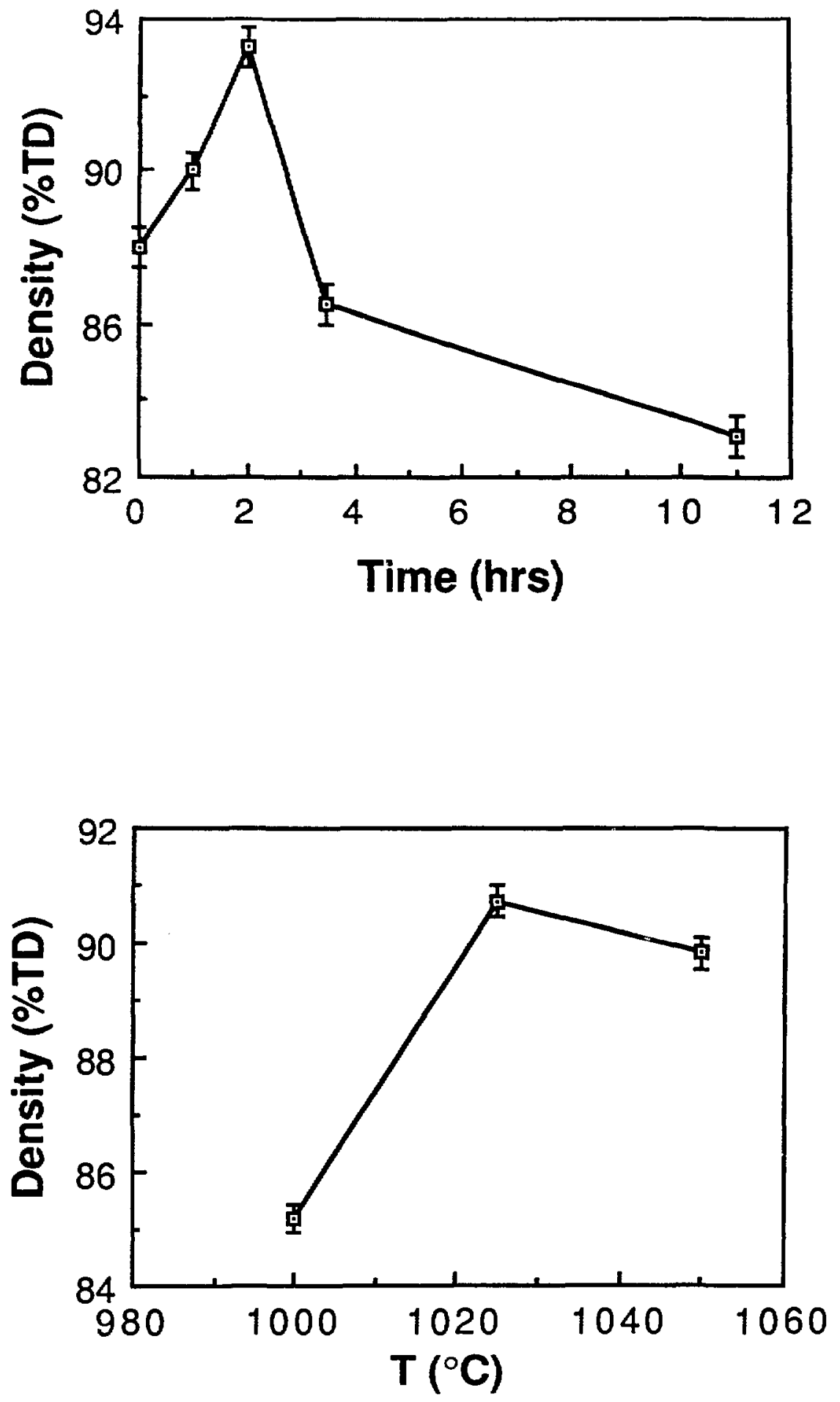

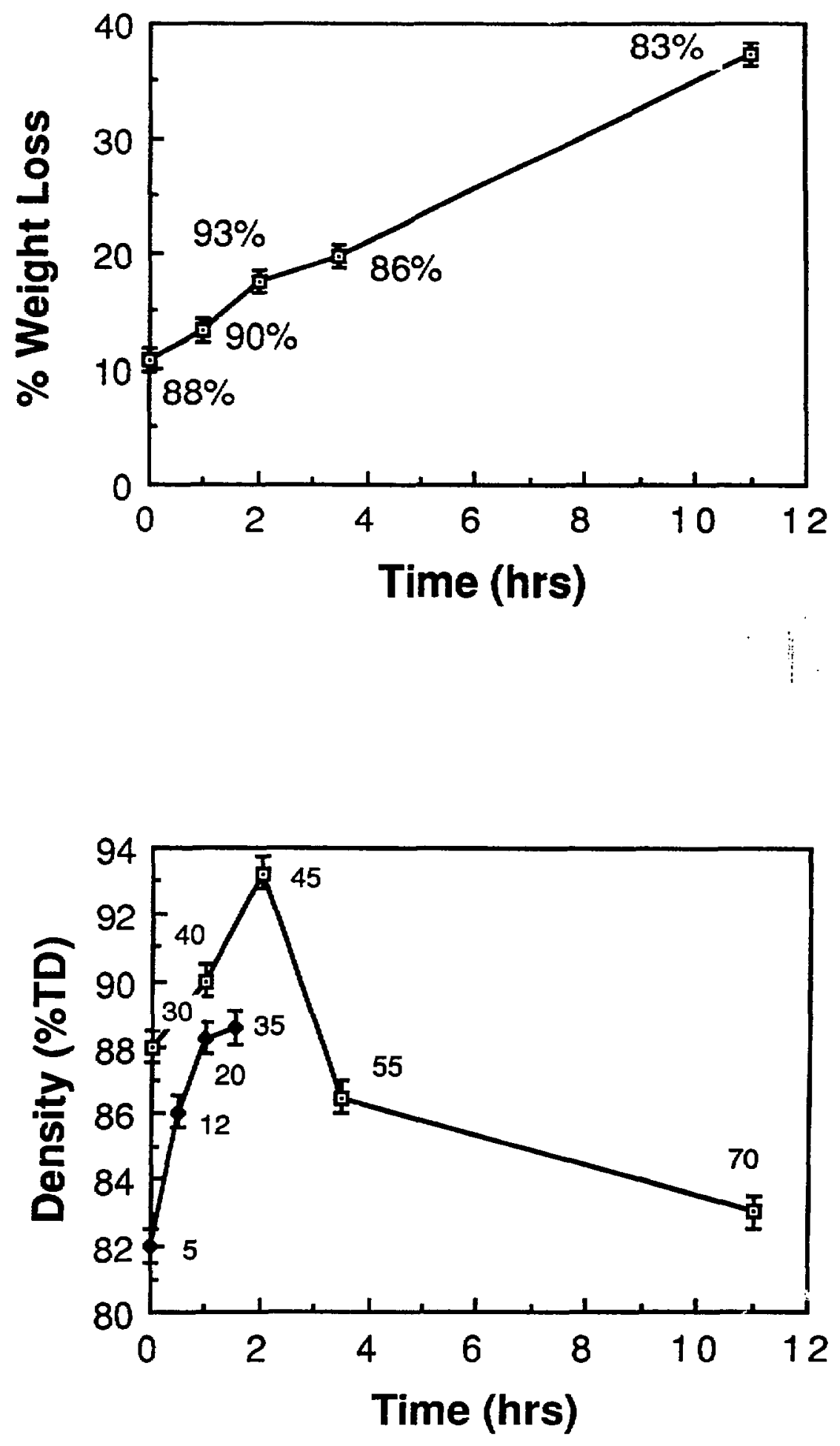

\section{- Figure 4 (C. Y. Chu et a1.)}




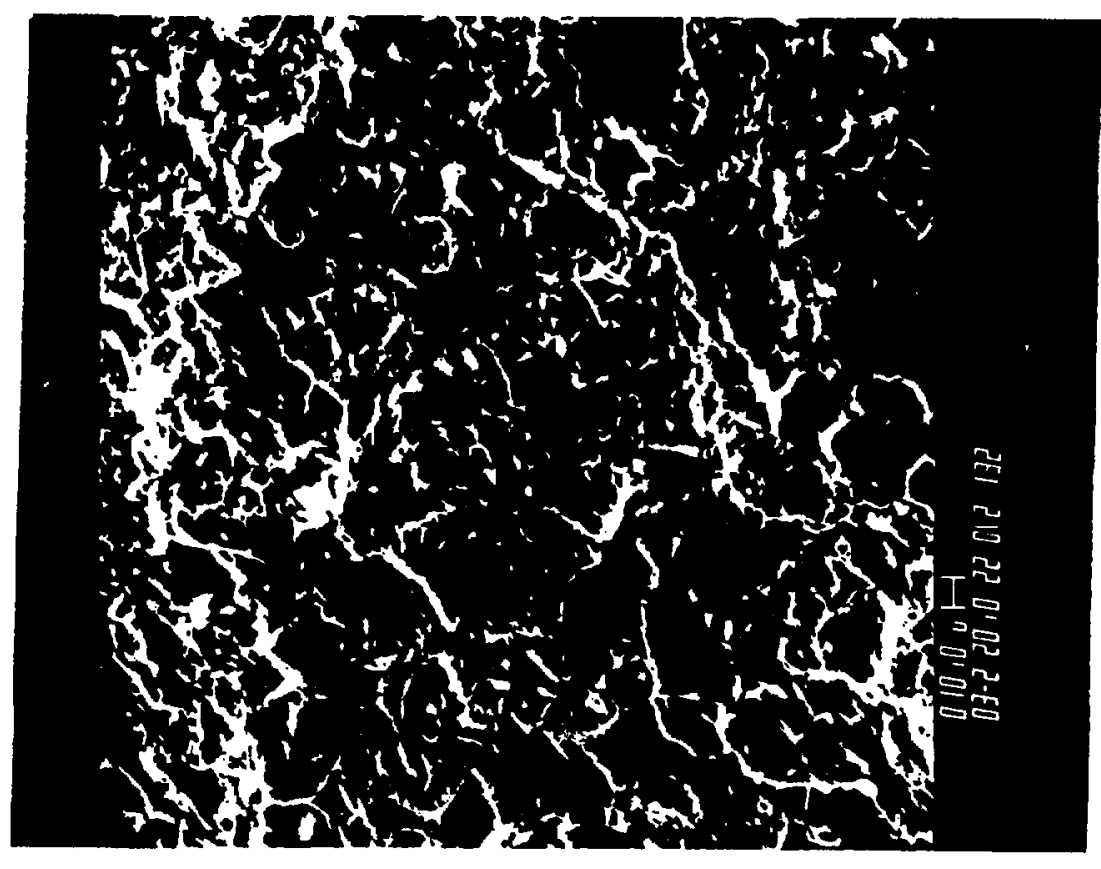

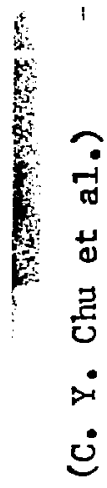

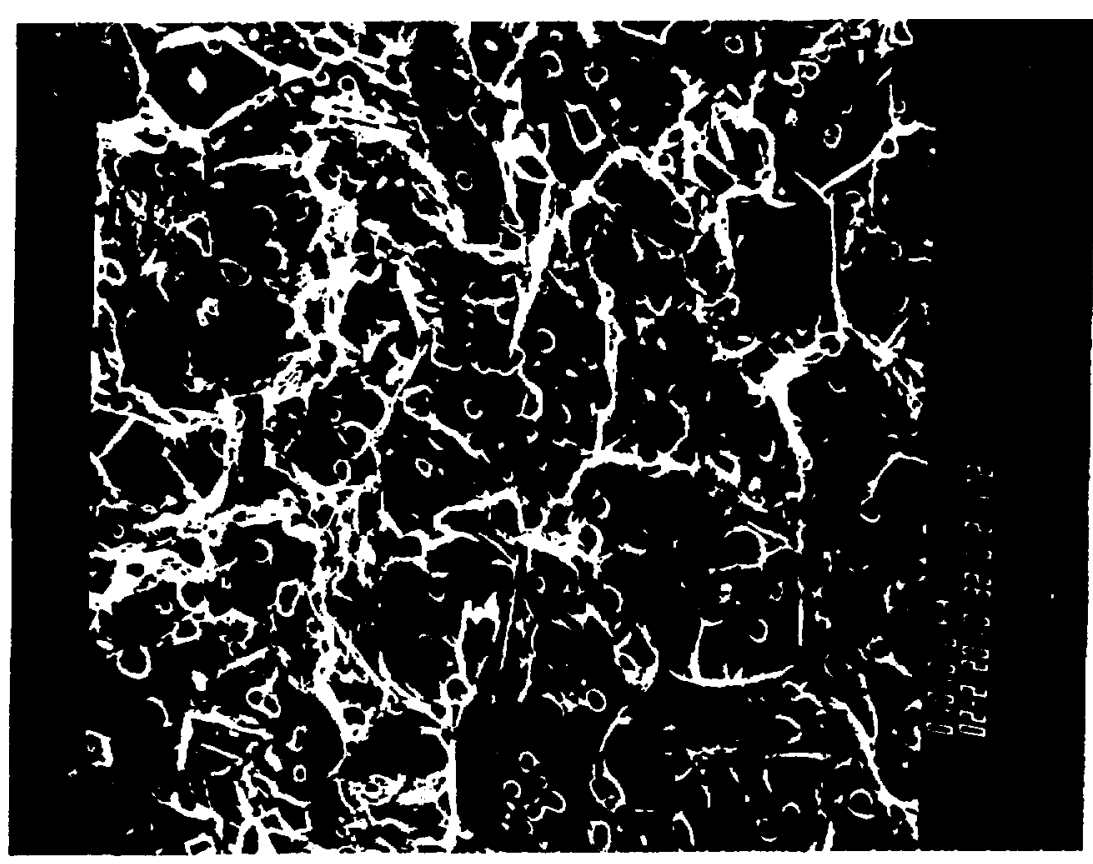

in 


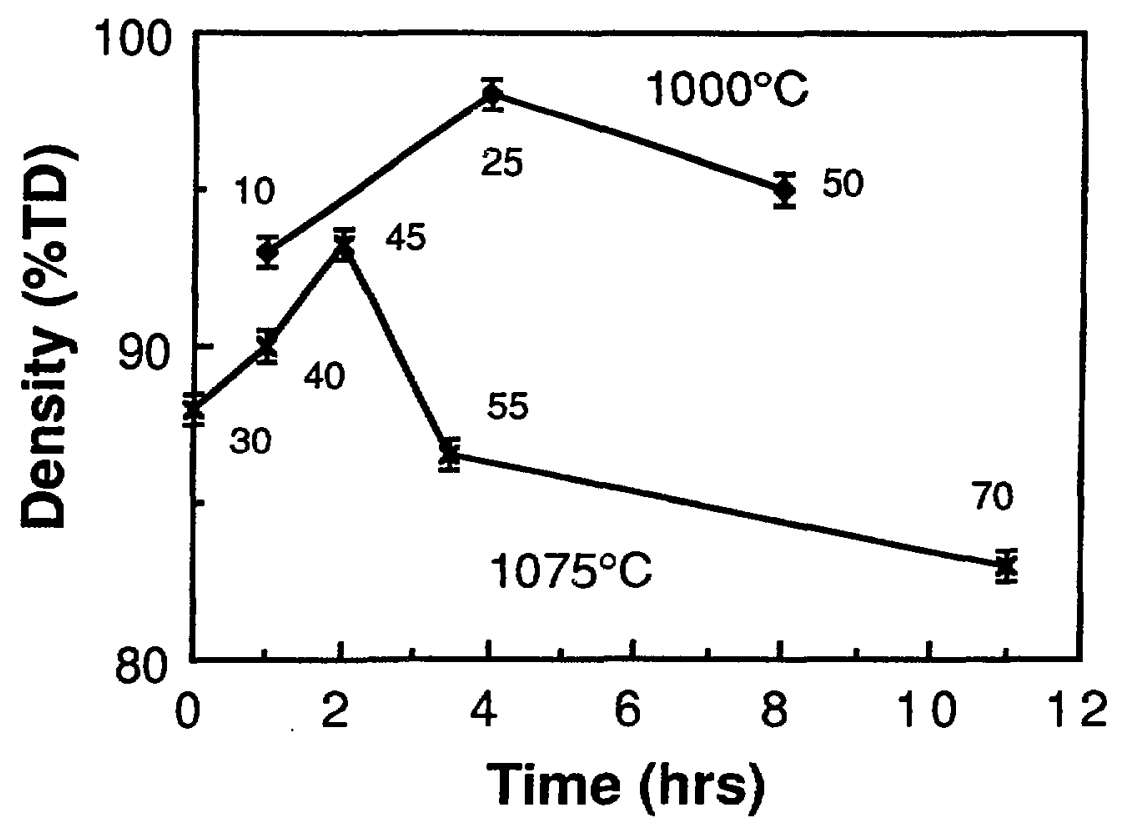

